\title{
An infant mouse model of brain damage in pneumococcal meningitis
}

\author{
Denis Grandgirard • Oliver Steiner • \\ Martin G. Täuber $\cdot$ Stephen L. Leib
}

Received: 23 July 2007 / Revised: 10 September 2007 / Accepted: 27 September 2007 / Published online: 16 October 2007

(C) Springer-Verlag 2007

\begin{abstract}
Bacterial meningitis due to Streptococcus pneumoniae is associated with an significant mortality rate and persisting neurologic sequelae including sensory-motor deficits, seizures, and impairments of learning and memory. The histomorphological correlate of these sequelae is a pattern of brain damage characterized by necrotic tissue damage in the cerebral cortex and apoptosis of neurons in the hippocampal dentate gyrus. Different animal models of pneumococcal meningitis have been developed to study the pathogenesis of the disease. To date, the infant rat model is unique in mimicking both forms of brain damage documented in the human disease. In the present study, we established an infant mouse model of pneumococcal meningitis. Eleven-days-old C57BL/6 $(n=299), \mathrm{CD} 1(n=42)$ and $\mathrm{BALB} / \mathrm{c}(n=14)$ mice were infected by intracisternal injection of live Streptococcus pneumoniae. Sixteen hours after infection, all mice developed meningitis as documented by positive bacterial cultures of the cerebrospinal fluid. Sixty percent of infected C57BL/6 mice survived more than $40 \mathrm{~h}$ after infection ( $50 \%$ of CD1, $0 \%$ of BALB/c). Histological evaluations of brain sections revealed apoptosis in the dentate gyrus of the hippocampus in $27 \%$ of infected C57BL/6 and in 5\% of infected CD1 mice. Apoptosis was confirmed by immunoassaying for active caspase3 and by TUNEL staining. Other forms of brain damage
\end{abstract}

D. Grandgirard · M. G. Täuber · S. L. Leib ( $\square)$

Institute for Infectious Diseases, University of Bern,

Friedbühlstrasse 51, 3010 Bern, Switzerland

e-mail: Stephen.leib@ifik.unibe.ch

O. Steiner

Theodor Kocher Institute,

University of Bern, Bern, Switzerland were found exclusively in C57BL/6, i.e. caspase-3 independent (pyknotic) cell death in the dentate gyrus in $2 \%$ and cortical damage in $11 \%$ of infected mice. This model may prove useful for studies on the pathogenesis of brain injury in childhood bacterial meningitis.

Keywords Pneumococcal meningitis - Brain damage · Infant rat model $\cdot$ Neuropathology $\cdot$ Paediatric infectious diseases

\section{Introduction}

Bacterial meningitis is an infection of the central nervous system (CNS) characterized by a strong inflammation of the meninges and the subarachnoid space [22, 24, 28]. Streptococcus pneumoniae is one of the major causative pathogens which causes the most severe form of the bacterial meningitis in terms of mortality and morbidity [42]. The introduction of new conjugate vaccines holds promises for decreasing the incidence of invasive diseases caused by $S$. pneumoniae, but they cover only a limited number of serotypes, and replacement by non-vaccine serotypes under vaccination pressure has been demonstrated [40]. S. pneumoniae infections, including pneumococcal meningitis, are therefore likely to remain an important health issue.

Pneumococcal meningitis (PM) in humans is associated with long-term sequelae including sensory-motor deficits, seizures, and impairments of learning and memory $[3,13$, 17]. Neurological sequelae occur in up to half of the survivors of PM [43]. In autopsy studies on patients who died from bacterial meningitis, damage in the CNS is characterized by tissue necrosis in the cortical hemispheres and by apoptotic cell death in the dentate gyrus [32]. Experimental 
data suggest that hippocampal apoptosis is associated with learning and memory deficits observed in survivors of bacterial meningitis [27].

Different animal models have been used to study the pathophysiology of brain damage in bacterial meningitis. In the rabbit model, hippocampal apoptosis is the predominant form of neuronal damage in experimental PM [7, 47]. In the adult rat, hemorrhages, cortical necrosis, and damage to the ciliated ependymal cells have been observed in experimental PM [18, 35], but hippocampal apoptosis is not a reproducible form of brain damage in this model. The adult mouse model is well suited to study defined aspects of the pathophysiology of bacterial meningitis, notably using gene knockout technology (reviewed by Paul et al. [36]). In terms of neuronal damage, focal necrosis with shrunken neurons showing nuclear pyknosis has been documented in the neocortex and the hippocampus of adult C57BL/6 mice. Condensed granule cells with apoptotic nuclei were occasionally found in this model [11]. Both caspase-dependent and independent forms of cell death have also been described in the dentate gyrus of adult mice [31]. The infant rat models of bacterial meningitis caused either by PM or Group B streptococcus (GBS) meningitis recapitulates important forms of neuronal damage, which have been documented in the human disease $[4,5]$. Neurons of the cortex undergo necrosis caused by ischemia as consequence of vasculitis, brain edema, and blood flow perturbations [4]. In the infant rat meningitis model, two forms of neuronal cell death have been identified in the dentate gyrus of the hippocampus. One form of brain damage predominantly found in meningitis caused by $S$. pneumoniae shows classical features of apoptosis (apoptotic bodies, activation of caspases), and affects immature neurons in the subgranular zone of the dentate gyrus, a region capable of neurogenesis. The second, caspase-3 independent cell death is predominantly found in meningitis caused by GBS. Herein, clusters of uniformly shrunken (pyknotic) cells were found throughout the whole dentate granule layer, affecting both immature and mature neurons [4].

Thus, to date, the infant rat model is unique in consistently reproducing both, hippocampal damage and cortical necrosis $[13,29]$. The present study aimed at translating the infant rat model to the infant mouse. To this end we chose mouse strains that have been used successfully in studies modeling brain pathologies associated with bacterial infections and that have been used as background strains in studies using knockout or transgenic techniques $[9,11,33,34,41]$ This would open the perspective of using knockout or transgenic animals to evaluate the involvement of different candidate genes in the pathophysiology of brain damage to the infant brain in pediatric pneumococcal meningitis.

\section{Materials and methods}

\section{Infecting organism}

We used a clinical isolate of Streptococcus pneumoniae (serotype 3 ) as previously described in the infant rat model $[2,26]$. Bacteria were cultured overnight in $10 \mathrm{ml}$ of brain heart infusion medium, diluted in fresh medium, and grown for another $6 \mathrm{~h}\left(35^{\circ} \mathrm{C}, \mathrm{CO}_{2} 5.5 \%\right)$ to logarithmic phase. The culture was centrifuged for $10 \mathrm{~min}$ at $5,000 \times \mathrm{g}$, and resuspended in sterile saline to the desired concentration and used for intracisternal injection. To confirm the accuracy of the inoculum size, serial decimal dilutions were prepared from $10^{-2}$ to $10^{-7}$ with $10 \mu \mathrm{l}$ of diluted and undiluted inoculum in sterile saline. Ten microlitre of each dilution was cultivated on blood agar plates (each on $1 / 6$ of a plate) at $35.2^{\circ} \mathrm{C}$ and $5.5 \% \mathrm{CO}_{2}$ for $12-18 \mathrm{~h}$.

\section{Animal model of meningitis}

The animal studies were approved by the Animal Care and Experimentation Committee of the Canton of Bern, Switzerland, and followed National Institutes of Health guidelines for the performance of animal experiments.

Nursing CD1 $(n=42), \mathrm{BALB} / \mathrm{c}(n=14)$, and C57BL/6 $(n=299)$ mouse pups (Charles River, Germany) were infected on postnatal day 11 by intracisternal injection of $10 \mu \mathrm{l}$ of saline containing a defined inoculum of S. pneumoniae using a 32-gauge needle.

The subsequent studies were performed in C57BL/6 mice. There, 11-day-old C57BL/6 pups weighting $5.346 \pm 0.81 \mathrm{~g}$ received an inoculum containing $\log _{10} 5.3 \pm 0.5 \mathrm{CFU} / \mathrm{ml}$ of $S$. pneumoniae. Uninfected C57BL/6 mice $(n=35)$ were injected with $10 \mu \mathrm{l}$ of sterile, pyrogen-free saline. Animals were returned to their dams; and at $16 \mathrm{~h}$ after infection, they were weighed and scored clinically including their ambulatory activity and their capability to right themselves with the following score: $1=$ coma; $2=$ does not turn upright when positioned on the back; $3=$ turns upright within $30 \mathrm{~s} ; 4=$ minimal ambulatory activity, turns upright $<5 \mathrm{~s} ; 5=$ normal.

Meningitis was documented by a quantitative culture of $5 \mu \mathrm{l}$ of cerebrospinal fluid (CSF) obtained by puncture of the cisterna magna at $16 \mathrm{~h}$ after infection followed by the initiation of the antibiotic treatment (ceftriaxone $100 \mathrm{mg} / \mathrm{kg}$ body weight, s.c. bid., Roche Pharma, Reinach, Switzerland). Moribund animals (score $\leq 2$ ) were killed for ethical reason by a lethal injection of pentobarbital $(100 \mathrm{mg} / \mathrm{kg}$, i.p., Nembutal, Abbott Laboratories).

\section{Histopathology}

In a subset of animals ( $n=136$ for infected, $n=3$ for noninfected) neuronal damage was assessed by cryosection and 
staining with cresyl violet. Animals were euthanized with a lethal injection of pentobarbital and perfused with $4 \%$ paraformaldehyde (PFA) in 0.1 M PBS pH 7.4 via the left cardial ventricle. Brains were removed, postfixed for $3 \mathrm{~h}$ in $4 \%$ PFA at $4^{\circ} \mathrm{C}$ and then cryo-protected for another 3 days in a solution of $18 \%$ sucrose in PBS at $4^{\circ} \mathrm{C}$. Animals that died unobserved or that died spontaneously before $18 \mathrm{~h}$ were not analyzed, because neurological damage starts to develop at around $20 \mathrm{~h}$ after infection [13].

Coronal sections $(45 \mu \mathrm{m})$ from the frontal (cortical), middle (ventricular), and dorsal (hippocampal) brain region were cut with a cryotome (Jung CM1800, Leica, Glattbrugg, Switzerland) and mounted on chrome-alum-gelatin coated glass slides. Slides were stained with cresyl violet (Nissl staining).

Cortical necrosis was defined as an area of reduced neuronal density with neurons displaying morphological features of necrosis, including cell swelling and loss of cytoarchitecture. Nissl-stained sections of frontal, middle, and dorsal brain region were scanned and analyzed with the public domain NIH Image software (http://rsb.info.nih.gov/ nih-image/). The quantity of cortical damage was expressed as the percentage of the whole cortex area displaying features of necrosis. A mean score of all evaluated sections (four sections of frontal, middle, and dorsal brain regions) was calculated per animal [37].

For quantification of apoptosis in the dentate gyrus, four sections of the dorsal brain region containing the dentate gyrus of the hippocampus were evaluated for each animal. Cells with morphologic features of apoptosis (condensed nuclei and one or more apoptotic bodies) were counted in three visual fields at a magnification of $400 \times$ in each of the four blades of the dentate gyrus. The following scoring system was used: $0-5$ cells/visual field $=0,6-20$ cells $=1,>20$ cells $=2$. A mean per animal was calculated from all slides evaluated [26].

\section{Immunofluorescence}

For immunofluorescence, brains were processed as described earlier. For selected immunohistochemical analyses paraffin-embedded sections were needed. To this end a subset of animals $(n=50)$ were perfused with phosphatebuffered saline (PBS), and brains were embedded in paraffin after fixation in a solution of methanol and acetic acid 95:5. Sections mounted on slides were incubated overnight at $4{ }^{\circ} \mathrm{C}$ with the following primary antibodies: goat $\alpha$-doublecortin 1:200 (DCX, Santa Cruz Laboratories, Santa Cruz, USA), rabbit $\alpha$-active caspase-3 1:500 (CM-1, BD Biosciences, Canada), mouse $\alpha$-neuronal specific nuclear protein 1:500 (NeuN, Chemicon International, Temecula, USA). Secondary antibodies, diluted 1:1,000 were: Cy3conjugated donkey $\alpha$-mouse and donkey $\alpha$-goat (Jackson
Laboratories, Maine, USA), Alexa 488-goat $\alpha$-rabbit (Molecular Probes, Eugene, USA). Finally nuclei were counterstained with 4',6-diamidino-2-phenylindole (DAPI).

All antibodies were diluted in a buffer consisting of a 1:1 [vol/vol] mixture of $0.5 \%$ bovine serum albumin in PBS and $0.5 \mathrm{M}$ Tris buffer [pH 7.6] in $0.88 \% \mathrm{NaCl}$ ).

Stained slides were examined by fluorescence microscopy (Zeiss Axiophot microscope equipped with a Hamamatsu digital camera) and images digitized (Open Lab 4.0.3 Software, Improvision). When necessary, contrast of the images was adjusted, using Photoshop 7.0.1 (Adobe Systems Inc.)

\section{TUNEL staining}

Staining for fragmented DNA, a hallmark of apoptosis, was performed on $10 \mu \mathrm{m}$ paraffin sections with the Fluorescein FragEL ${ }^{\mathrm{TM}}$ DNA fragmentation detection kit (Calbiochem ${ }^{\circledR}$, Merck, Darmstadt, Germany), which incorporates fluorescein-labeled deoxynucleotides at the $3^{\prime}-\mathrm{OH}$ end of DNA fragments. The assay was performed according to the instructions provided by the manufacturer.

Statistical analysis

Survival was analyzed by Kaplan-Meier curves. Differences between groups for the number of animals with or without damage were determined with Chi-square test. Difference in the extent of cortical or hippocampal damage between two groups was analyzed with unpaired $t$-test or with nonparametric Mann-Whitney test after testing for data distribution. All tests were performed using GraphPad Prism 4.01.

\section{Results}

\section{Clinical parameters}

Intracisternal injection of $S$. pneumoniae, resulted in the development of meningitis in all mice, as confirmed by positive culture of $S$. pneumoniae in the CSF. Bacterial titers at $16 \mathrm{~h}$ after infection ranged from $\log _{10} 6.78 \pm$ $0.5 \mathrm{CFU} / \mathrm{ml}(n=30)$ in CD1 mice to $\log _{10} 7.2 \pm 0.53$ ( $n=145$ ) CFU/ml in C57BL/6 mice. The disease severity in infected BALB/c mice was critical at the scheduled time of CSF sampling. Therefore, intracisternal puncture was omitted for ethical reasons and, in consequence, data on $\mathrm{CSF}$ bacterial titers in BALB/c mice were not available. In the range of inocula tested to establish the model in C57BL/ 6 (between $\log _{10} 2.3$ and $\log _{10} 4.11 \mathrm{CFU}$ ), no correlation was found either between the size of the inoculum and mortality, or between bacterial titers at $16 \mathrm{~h}$ after infection and mortality (data not shown). 
Disease severity and mortality

Survival was analyzed by Kaplan-Meier curves, including all infected animals from the time of infection up to $40 \mathrm{~h}$ after infection, at which time surviving animals were killed. Animals were analyzed in groups for each mouse strain tested. Animals killed for ethical reasons (clinical score $\leq 2$ ) were assigned the time of killing as time of death. Animals killed with a clinical score $>2$ for timecourse analysis or at the end of the experiment were considered as censored subjects. C57BL/6 mice $(n=299)$ had a median survival time of $36 \mathrm{~h}$, whereas the median survival was shorter in CD-1 (20.5 h, $n=56)$ and BALB/c $(17 \mathrm{~h}$, $n=12$ ) mice (Fig. 1). Due to the longer survival time, the subsequent series of experiments were performed in C57BL/6 mice. An important litter-to-litter variability was evident as illustrated by the observation that in one litter, animals showed nearly a $100 \%$ mortality rate over $40 \mathrm{~h}$ after infection, whereas in another litter, infection by the identical experimental procedure caused low mortality (approx. 30\%) within $40 \mathrm{~h}$.

In the subgroup of C57BL/6 mice $(n=136)$ analyzed for neuronal damage, the 28 animals killed before $40 \mathrm{~h}$ after infection with a clinical score $>2$ for time-course studies were censored. From the remaining 108 animals, 29 animals (27\%) died spontaneously, while 14 animals (13\%) had to be killed for ethical reasons (clinical score $\leq 2$ ). Sixty-five animals (60\%) survived until the end of the analysis

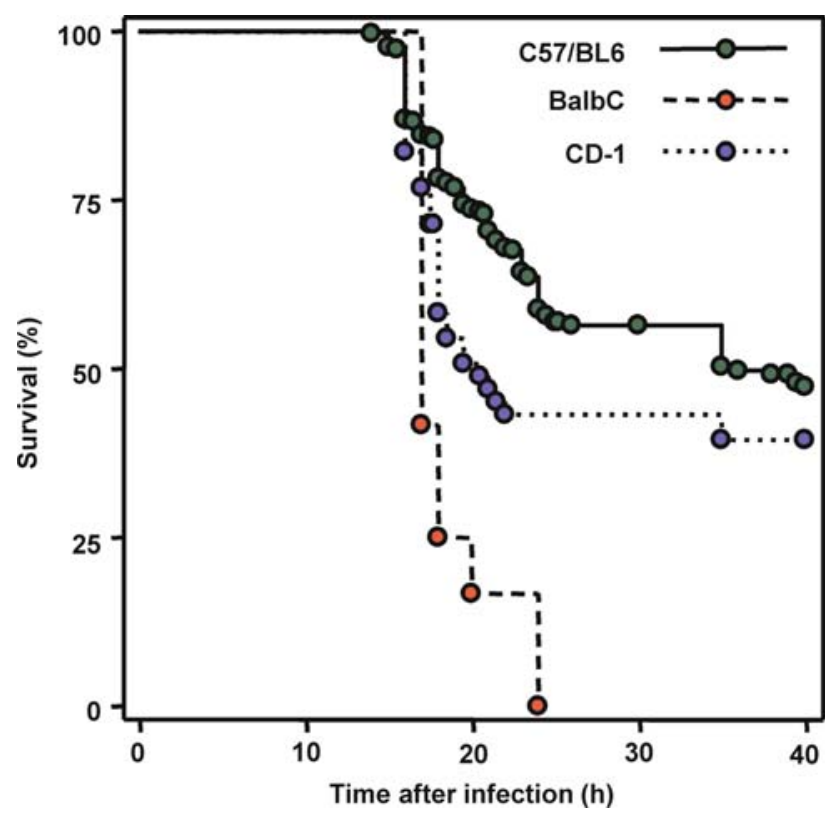

Fig. 1 Kaplan-Meier Survival Curves of C57BL/6 (green), CD1 (blue) and, BALB/c (red) mice infected by intracisternal infection with Streptococcus pneumoniae. Results are expressed as percentage of survival over time with death either spontaneous or by killing for ethical reasons (severe disease with a clinical score $<2$ )
(40 $\mathrm{h}$ after infection). At that time, animals resumed a normal activity. The results from trials with 42 infected CD1 mice showed $20(48 \%)$ spontaneous deaths, $1(2 \%)$ mouse euthanized with a clinical score of 2 and $21(50 \%)$ that survived until the end of the analysis. Finally, from 14 infected BALB/c mice, 10 (71\%) died spontaneously, and the remaining $4(29 \%)$ had to be killed because of severe clinical disease (score $\leq 2$ ).

Histopathology

The extent of apoptosis was analyzed at different time points after infection in C57BL/6 mice (Fig. 3). A peak of apoptosis was documented between 30 and $40 \mathrm{~h}$ after infection. This is in agreement to what had been observed previously in the infant rat model of pneumococcal meningitis [13]. Sporadically, cells showed pyknotic and shrunken nuclei, spanning entire regions of the dentate gyrus layer (Fig. 2c). This form of non-apoptotic neuronal cell death has been previously described to sporadically occur in the infant rat model of pneumococcal meningitis [4]. Histopathologic assessment at $40 \mathrm{~h}$ after infection in C57BL/6 mice $(n=65)$ showed apoptosis in the inner layer of the dentate gyrus in 22 animals (34\%) (Fig. 2b; Table 1); and in 14 animals (11\%) neuronal damage in the cortex was documented (Fig. 2a; Table 1). Few or no apoptotic cells (mean apoptosis score $=0, n=3$ ) were detected in uninfected control animals.

From 21 infected CD1 mice, which survived until $40 \mathrm{~h}$, $2(10 \%)$ developed apoptosis in the dentate gyrus; and no animal had cortical damage or pyknotic cell death in the dentate gyrus (Table 1). Neither apoptosis nor pyknotic cell death in the dentate gyrus nor the cortical damage was observed among the 14 infected BALB/c mice.

There was no correlation between the CSF bacterial titer determined at $16 \mathrm{~h}$ after infection and the amount of apoptotic cells in the dentate gyrus or the extent of neuronal damage in the cortex in any of the three mouse strains (data not shown).

Immunofluorescence studies

The nature of hippocampal cell death was assessed by the detection of fragmented DNA by TUNEL assay and immunostaining for active caspase-3, a key enzyme of apoptosis on brain slices from C57BL/6 mice. The histomorphological identification of apoptosis was confirmed by positive TUNEL and caspase-3 staining in cells of the inner layer of the dentate gyrus (Figs. 2e, 4b). Regions containing pyknotic cells were negative for both, caspase-3 immunostaining and TUNEL assay (Figs. 2d, 4a). Immunostainings with an antibody against doublecortin (DCX), a marker for neuronal progenitor cells and early postmitotic immature 

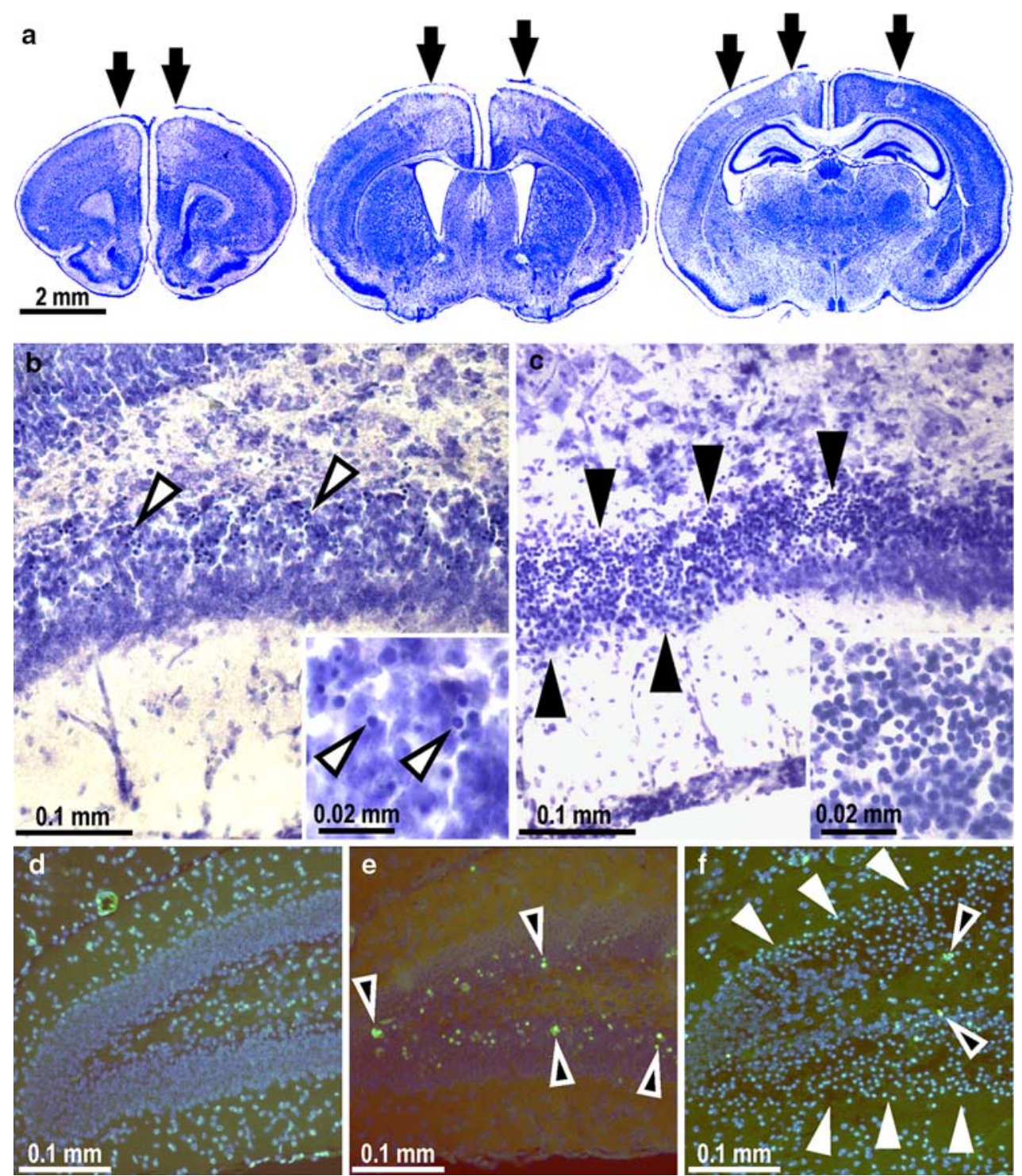

Fig. 2 Characterization of brain damage in infant C57BL/6 mice at $40 \mathrm{~h}$ of experimental meningitis due to $S$. pneumoniae. Sections were stained with Cresyl violet $(\mathbf{a}-\mathbf{c})$ or by TUNEL counterstained with DAPI $(\mathbf{d}-\mathbf{f})$. a Neuronal injury in the cortex in serial coronal whole brain sections, visible as areas of necrosis and reduced neuronal density (arrows). b Apoptosis, characterized by clustered cells with fragmented and condensed nuclei, was localized to the subgranular zone of the hippocampal dentate gyrus (open arrowheads). c Cells exhibiting features of pyknotic cell death with dense and shrunken nuclei were uniformly spread throughout the entire width of the dentate gyrus (closed arrowheads). d No TUNEL positive cells were detected in uninfected animals injected with sterile saline. e Apoptotic, TUNEL positive cells (open arrowheads) were documented in the subgranular zone of infected animals, co-localizing with the region of apoptotic bodies in cresyl-stained sections. f Areas of pyknotic cell death (closed arrowheads) were devoid of TUNEL positive cells, whereas adjacent subgranular regions displayed scattered clusters of TUNEL positive apoptotic cells (open arrowheads)

Table 1 Histopathological findings in mice with experimental meningitis due to Streptococcus pneumoniae at $40 \mathrm{~h}$ after infection

\begin{tabular}{|c|c|c|c|c|}
\hline Strain $(n)$ & $\begin{array}{l}\text { Incidence of apoptosis } \\
\text { (score } \geq 0.25 \text { ) }\end{array}$ & $\begin{array}{l}\text { Apoptosis score } \\
(\text { mean } \pm \mathrm{SD})\end{array}$ & $\begin{array}{l}\text { Incidence of } \\
\text { cortical damage }\end{array}$ & $\begin{array}{l}\text { Cortical damage } \\
\text { ( } \% \text { of cortex median [range]) }\end{array}$ \\
\hline C57BL/6 (65) & $34 \%$ & $0.87 \pm 0.49$ & $11 \%$ & $4.83[0.45-23]$ \\
\hline CD1 (21) & $10 \%$ & $0.61 \pm 0.28$ & $0 \%$ & 0 \\
\hline
\end{tabular}

The incidence of apoptosis and of cortical damage was determined in C57BL/6 and in CD1 mice at $40 \mathrm{~h}$ after infection. Apoptosis was expressed as a score and the extent of cortical damage as the percentage of total cortical area in the respective brain section 
neurons [1], showed positive cells mostly in the inner layer of the dentate gyrus, whereas cells expressing a marker for mature neurons (NeuN) were located mostly in the outer layer. Most of the caspase- 3 positive cells were observed in the inner layer, and were clearly situated outside the cell layer immunoreactive for NeuN (Fig. 4c). Occasionally, cells double-positive for active caspase- 3 and DCX could be observed (Fig. 4d).

These findings suggest that, in agreement with what was found in the infant rat, immature rather than fully differentiated neurons undergo apoptosis in experimental pneumococcal meningitis [15].

\section{Discussion}

Here, we report on the translation of an established infant rodent model of pneumococcal meningitis from the rat to mice $[4,13]$. Experimental pneumococcal meningitis was documented in all inoculated mice as confirmed by positive bacterial cultures from CSF samples drawn at $16 \mathrm{~h}$ after infection. The method of direct infection behind the bloodbrain barrier is more efficient than methods of hematogenous infection, where meningitis develops only in around $50 \%$ of infected animals by intranasal or intraperitoneal infection $[38,44]$. The direct route of infection into the cisterna magna has been shown previously to be suitable for generating bacterial meningitis in a high percentage of infected infant rats $[4,25]$. It is therefore particularly well suited to study pathophysiological events related to the development of neuronal injury. The majority of cases of bacterial meningitis is caused in association with sinusitis and otitis, where an infection of the meningeal space "via continuitatem" is postulated [21].

The size of the inoculum used for infection $\left(2 \times 10^{2}-\right.$ $2 \times 10^{4} \mathrm{CFU} / \mathrm{animal}$ ) of infant mice did not correlate with the survival rates in all three mouse strains. However, the range of bacterial inocula tested in this study was not as broad as in other studies [8] and was primarily based on the size of inoculum used in the infant rat model [13], adapted for weight. In the infant rat model of pneumococcal meningitis a mortality of $30-50 \%$ is observed at $40 \mathrm{~h}$ after infection. The mortality varies depending on a number of factors, e.g. the amount of bacteria used for infection and adjuvant therapies [16]. A study by Chiavolini et al. [8] used a much broader range $\left(10^{1}\right.$ to $10^{5} \mathrm{CFU}$ of type $4 \mathrm{~S}$. pneumoniae/animal) and demonstrated a correlation of survival in a similar adult MF1 mice model.

Susceptibility and resistance to pneumococcal disease depending on the genetic background of the mice strain used has been studied to some extent [19]. The current knowledge is that differences in susceptibility result from a combination of both host and pathogen determinants.

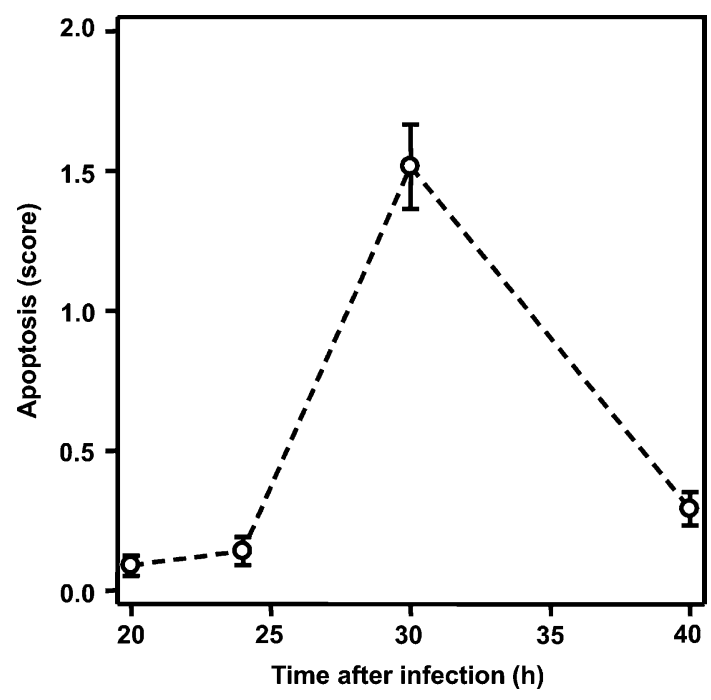

Fig. 3 Apoptosis in the dentate gyrus of infant C57BL/6 mice infected with $S$. pneumoniae. Apoptosis score (mean \pm SEM) over time after infection (threshold $\geq 0.25$ ). The extent of apoptosis shows a peak at $30 \mathrm{~h}$ after infection

$\mathrm{BALB} / \mathrm{c}$ mice displayed an increased resistance upon intranasal challenge with a serotype 2 (D39) when compared with eight other inbred strains, which might be associated with a different recruitment and/or function of neutrophils [14]. However, in another study using intranasal challenge with a serotype 4 (TIGR4), BALB/c and C57BL/6 displayed a similar susceptibility, although BALB/c mice were more prone to develop meningitis [39]. Bacterial strains also differ in their ability to colonize specific host compartments. For example, intranasal challenge with serotype 2 led to sepsis, whereas serotype 3 caused pneumoniae and serotype 4 meningitis [33]. In another study [39], serotype 4 caused the most-severe invasive disease, whereas serotype 1 caused low-level bacteremia without disease symptoms. In the context of susceptibility, the method of inoculation is also important, and direct intracisternal injection may well differ from other route of infection, because of the specific immunological environment in the brain compartment.

In the present study, BALB/c mice had a higher mortality than CD1 and C57BL/6 mice. Nonetheless, mortality could not be predicted by the size of the infectious challenge within the narrow range of inocula used in this study.

To characterize the pattern of neuronal injury encountered in experimental PM, different animal models were set up. Neuronal injury in the hippocampus was the only form of damage consistently present in an experimental model of PM in adult rabbits [47]. Until recently, in adult rat and mouse models of PM, the simultaneous occurrence of both pattern of neuronal damage in the cortex and in the hippocampal formation was rarely documented, and only severely ill mice were seen to display histomorphological evidence of brain injury in the cortex and in the hippocampus 

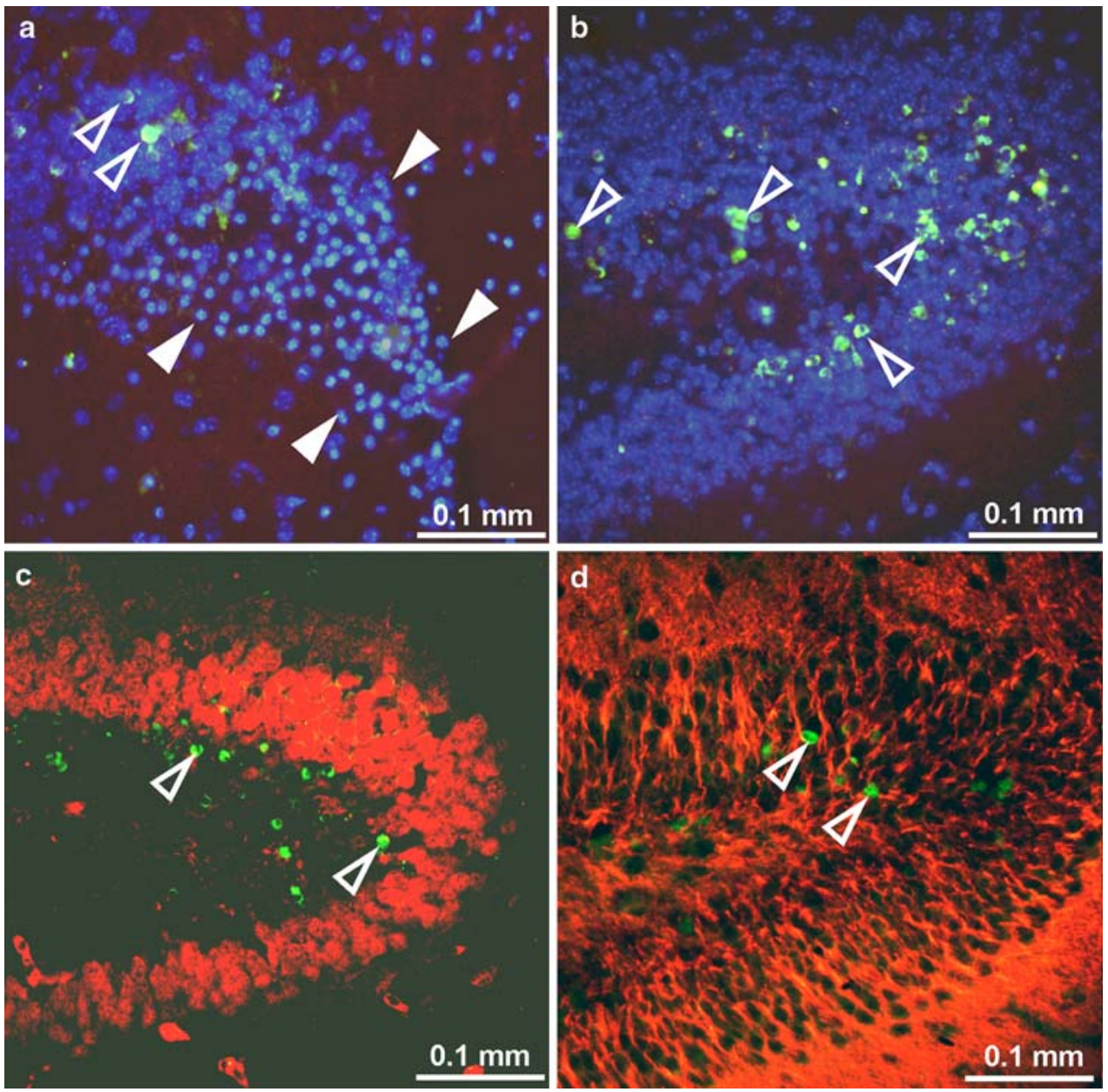

Fig. 4 Characterization of cell death by immunofluorescence in the hippocampal dentate gyrus of infant mice $40 \mathrm{~h}$ after infection. Immunohistochemistry was performed for active caspase-3 (a-d), NeuN (c) and doublecortin (d). Sections were counterstained with DAPI $(\mathbf{a}, \mathbf{b})$. Two distinct forms of cell death are present. a A caspase-independent cell death, characterized by pyknotic nuclei (closed arrowheads) distinct from cells exhibiting positive immunoreactivity for active-caspase-3 (green; open arrowheads). b Apoptotic cell death, characterized by

[8, 11]. More recently, Mitchell et al. [31] demonstrated evidence for the involvement of apoptosis in the DG of adult C57BL/6 or mixed C57BL/6X129/FVB mice. To our knowledge, the infant rat model of PM is unique in consistently producing both hippocampal damage and focal necrosis in the cerebral cortex $[2,4,5,13,15,27,29,30]$. Neuronal damage in the cortex of infected infant rat brains showed features of necrosis. In several studies investigating cortical brain damage, ischemia has been identified as an important contributor to this form of brain injury during meningitis [10, 25].

The histological results of the present study (Table 1; Figs. 2,3) are in agreement with the above described previous findings $[4,13]$. The present infant mouse model exhibits all three entities of neuronal brain damages found in fragmented nuclei and positive immunoreactivity for active-caspase-3 (open arrowheads in a-d). c Caspase- 3 positive cells with apoptotic morphology (green, arrowheads) are limited to the inner layer and the hilus region of the dentate gyrus and are largely excluded from the hippocampal gyrus dentatus layer containing mature neurons with positive NeuN immunoreactivity. (d) Apoptotic cells co-localize with an area containing neuronal progenitor cells staining doublecortinpositive

patients and in the infant rat model of PM [4, 13, 32], i.e. necrosis in the cortex, apoptotic and "pyknotic" cell death in the DG (Fig. 2). Apoptosis, as confirmed by positive staining for TUNEL and active caspase-3, was predominantly present in the subgranular zone of the DG in $34 \%$ of surviving C57BL/6 and in $11 \%$ of CD1 mice. Pyknotic cell death occurred in few C57BL/6 mice affecting the entire width of the DG band, which includes mature and immature neurons. Co-localization of DCX and active caspase-3 in the subgranular layer of the DG (Fig. 4d) further supports the concept that immature neurons, rather than fully differentiated neurons undergo apoptosis in pneumococcal meningitis $[4,15]$.

In conclusion, an infant mouse model of $S$. pneumoniae meningitis that exhibits neuronal brain injury in the cortex 
and the hippocampus reflecting the histomorphological findings in the human disease has been successfully established. The use of knockout mice has offered new insights into the role of different cytokines [12, 45, 46], proteases [6], regulator proteins [20], and oxidants [23] involved in the inflammatory cascade during pneumococcal meningitis. The present model enables the use of knockout transgenic techniques in the investigations of specific pathogenetic aspects of neuronal damage consecutive to pneumococcal meningitis in infancy.

Acknowledgments We thank Franziska Simon, Angela Bühlmann and Jürg Kummer for their excellent technical work. This work was supported by grants from the Swiss National Science Foundation (632066057, and from the NIH (2P50NS035902-06).

\section{References}

1. Abrous DN, Koehl M, Le Moal M (2005) Adult neurogenesis: from precursors to network and physiology. Physiol Rev 85:523-569

2. Auer M, Pfister LA, Leppert D, Täuber MG, Leib SL (2000) Effects of clinically used antioxidants in experimental pneumococcal meningitis. J Infect Dis 182:347-350

3. Bedford H, Louvois J, Halket S, Peckham C, Hurley R, Harvey D (2001) Meningitis in infancy in England and Wales: follow up at age 5 years. BMJ 323:533-536

4. Bifrare YD, Gianinazzi C, Imboden H, Leib SL, Täuber MG (2003) Bacterial meningitis causes two distinct forms of cellular damage in the hippocampal dentate gyrus in infant rats. Hippocampus 13:481-488

5. Bifrare YD, Kummer J, Joss P, Täuber MG, Leib SL (2005) Brainderived neurotrophic factor protects against multiple forms of brain injury in bacterial meningitis. J Infect Dis 191:40-45

6. Bottcher T, Spreer A, Azeh I, Nau R, Gerber J (2003) Matrix metalloproteinase-9 deficiency impairs host defense mechanisms against Streptococcus pneumoniae in a mouse model of bacterial meningitis. Neurosci Lett 338:201-204

7. Braun JS, Novak R, Herzog KH, Bodner SM, Cleveland JL, Tuomanen EI (1999) Neuroprotection by a caspase inhibitor in acute bacterial meningitis. Nat Med 5:298-302

8. Chiavolini D, Tripodi S, Parigi R, Oggioni MR, Blasi E, Cintorino M, Pozzi G, Ricci S (2004) Method for inducing experimental pneumococcal meningitis in outbred mice. BMC Microbiol 4:36

9. Dominguez-Punaro MC, Segura M, Plante MM, Lacouture S, Rivest $S$, Gottschalk M (2007) Streptococcus suis serotype 2, an important swine and human pathogen, induces strong systemic and cerebral inflammatory responses in a mouse model of infection. J Immunol 179:1842-1854

10. Förderreuther S, Tatsch K, Einhäupl KM, Pfister HW (1992) Abnormalities of cerebral blood flow in the acute phase of bacterial meningitis in adults. J Neurol 239:431-436

11. Gerber J, Raivich G, Wellmer A, Noeske C, Kunst T, Werner A, Bruck W, Nau R (2001) A mouse model of Streptococcus pneumoniae meningitis mimicking several features of human disease. Acta Neuropathol (Berl) 101:499-508

12. Gerber J, Bottcher T, Hahn M, Siemer A, Bunkowski S, Nau R (2004) Increased mortality and spatial memory deficits in TNFalpha-deficient mice in ceftriaxone-treated experimental pneumococcal meningitis. Neurobiol Dis 16:133-138

13. Gianinazzi C, Grandgirard D, Imboden H, Egger L, Meli DN, Bifrare DY, Joss PC, Täuber MG, Borner C, Leib SL (2003) Caspase-
3 mediates hippocampal apoptosis in pneumococcal meningitis. Acta Neuropathol 105:499-507

14. Gingles NA, Alexander JE, Kadioglu A, Andrew PW, Kerr A, Mitchell TJ, Hopes E, Denny P, Brown S, Jones HB, Little S, Booth GC, McPheat WL (2001) Role of genetic resistance in invasive pneumococcal infection: identification and study of susceptibility and resistance in inbred mouse strains. Infect Immun 69:426-434

15. Grandgirard D, Bifrare YD, Pleasure SJ, Kummer J, Leib SL, Täuber MG (2007) Pneumococcal meningitis induces apoptosis in recently postmitotic immature neurons in the dentate gyrus of neonatal rats. Dev Neurosci 29:134-142

16. Grandgirard D, Schurch C, Cottagnoud P, Leib SL (2007) Prevention of brain injury by the nonbacteriolytic antibiotic daptomycin in experimental pneumococcal meningitis. Antimicrob Agents Chemother 51:2173-2178

17. Grimwood K, Anderson P, Anderson V, Tan L, Nolan T (2000) Twelve year outcomes following bacterial meningitis: further evidence for persisting effects. Arch Dis Child 83:111-116

18. Hirst RA, Gosai B, Rutman A, Andrew PW, O'Callaghan C (2003) Streptococcus pneumoniae damages the ciliated ependyma of the brain during meningitis. Infect Immun 71:6095-6100

19. Kadioglu A, Andrew PW (2005) Susceptibility and resistance to pneumococcal disease in mice. Brief Funct Genomic Proteomic 4:241-247

20. Kastenbauer S, Koedel U, Pfister HW (1999) Role of peroxynitrite as a mediator of pathophysiological alterations in experimental pneumococcal meningitis. J Infect Dis 180:1164-1170

21. Kastenbauer S, Pfister HW (2003) Pneumococcal meningitis in adults: spectrum of complications and prognostic factors in a series of 87 cases. Brain 126:1015-1025

22. Kim KS (2003) Pathogenesis of bacterial meningitis: from bacteraemia to neuronal injury. Nat Rev Neurosci 4:376-385

23. Koedel U, Paul R, Winkler F, Kastenbauer S, Huang PL, Pfister HW (2001) Lack of endothelial nitric oxide synthase aggravates murine pneumococcal meningitis. J Neuropathol Exp Neurol 60:1041-1050

24. Koedel U, Scheld WM, Pfister HW (2002) Pathogenesis and pathophysiology of pneumococcal meningitis. Lancet Infect Dis 2:721-736

25. Leib SL, Kim YS, Chow LL, Sheldon RA, Täuber MG (1996) Reactive oxygen intermediates contribute to necrotic and apoptotic neuronal injury in an infant rat model of bacterial meningitis due to group B streptococci. J Clin Invest 98:2632-2639

26. Leib SL, Leppert D, Clements J, Täuber MG (2000) Matrix metalloproteinases contribute to brain damage in experimental pneumococcal meningitis. Infect Immun 68:615-620

27. Leib SL, Heimgartner C, Bifrare YD, Loeffler JM, Täuber MG (2003) Dexamethasone aggravates hippocampal apoptosis and learning deficiency in pneumococcal meningitis in infant rats. Pediatr Res 4:4

28. Leib SL, Täuber MG (2004) Pathogenesis and pathophysiology of bacterial infections. In: Scheld WM, Whitley RJ, Marra CM (eds) Infections of the central nervous system. Lippincott Williams \& Wilkins, Philadelphia, pp 331-346

29. Loeffler JM, Ringer R, Hablutzel M, Täuber MG, Leib SL (2001) The free radical scavenger alpha-phenyl-tert-butyl nitrone aggravates hippocampal apoptosis and learning deficits in experimental pneumococcal meningitis. J Infect Dis 183:247-252

30. Meli DN, Coimbra RS, Erhart DG, Loquet G, Bellac CL, Täuber MG, Neumann U, Leib SL (2006) Doxycycline reduces mortality and injury to the brain and cochlea in experimental pneumococcal meningitis. Infect Immun 74:3890-3896

31. Mitchell L, Smith SH, Braun JS, Herzog KH, Weber JR, Tuomanen EI (2004) Dual phases of apoptosis in pneumococcal meningitis. J Infect Dis 190:2039-2046 
32. Nau R, Soto A, Bruck W (1999) Apoptosis of neurons in the dentate gyrus in humans suffering from bacterial meningitis. J Neuropathol Exp Neurol 58:265-274

33. Orihuela CJ, Gao G, McGee M, Yu J, Francis KP, Tuomanen E (2003) Organ-specific models of Streptococcus pneumoniae disease. Scand J Infect Dis 35:647-652

34. Orihuela CJ, Fillon S, Smith-Sielicki SH, El Kasmi KC, Gao G, Soulis K, Patil A, Murray PJ, Tuomanen EI (2006) Cell wall-mediated neuronal damage in early sepsis. Infect Immun 74:3783-3789

35. Ostergaard C, Brandt C, Konradsen HB, Samuelsson S (2004) Differences in survival, brain damage, and cerebrospinal fluid cytokine kinetics due to meningitis caused by 3 different Streptococcus pneumoniae serotypes: evaluation in humans and in 2 experimental models. J Infect Dis 190:1212-1220

36. Paul R, Koedel U, Pfister HW (2005) Development of adjunctive therapies for bacterial meningitis and lessons from knockout mice. Neurocrit Care 2:313-324

37. Pfister L-A, Tureen JH, Shaw S, Christen S, Ferriero DM, Täuber MG, Leib SL (2000) Endothelin inhibition improves cerebral blood flow and is neuroprotective in pneumococcal meningitis. Ann Neurol 47:329-335

38. Rodriguez AF, Kaplan SL, Hawkins EP, Mason EO Jr (1991) Hematogenous pneumococcal meningitis in the infant rat: description of a model. J Infect Dis 164:1207-1209

39. Sandgren A, Albiger B, Orihuela CJ, Tuomanen E, Normark S, Henriques-Normark B (2005) Virulence in mice of pneumococcal clonal types with known invasive disease potential in humans. J Infect Dis 192:791-800

40. Singleton RJ, Hennessy TW, Bulkow LR, Hammitt LL, Zulz T, Hurlburt DA, Butler JC, Rudolph K, Parkinson A (2007) Invasive pneumococcal disease caused by nonvaccine serotypes among alaska native children with high levels of 7-valent pneumococcal conjugate vaccine coverage. JAMA 297:1784-1792

41. Sura P, Srebro Z, Macura B, Majewska M, Zajac K, Szczepanik M (2006) Lipopolysaccharide aggravates cerebral pathology in B10.PL-derived CD1-/-, beta2m-/-, TCRalpha-/-, and TCRdelta-/knockout mice. Folia Biol (Krakow) 54:139-144

42. Swartz MN (2004) Bacterial meningitis-a view of the past 90 years. N Engl J Med 351:1826-1828

43. van de Beek D, Schmand B, de Gans J, Weisfelt M, Vaessen H, Dankert J, Vermeulen M (2002) Cognitive impairment in adults with good recovery after bacterial meningitis. J Infect Dis 186:1047-1052

44. Zwijnenburg PJ, van der Poll T, Florquin S, van Deventer SJ, Roord JJ, van Furth AM (2001) Experimental pneumococcal meningitis in mice: a model of intranasal infection. J Infect Dis 183:1143-1146

45. Zwijnenburg PJ, van der Poll T, Florquin S, Akira S, Takeda K, Roord JJ, van Furth AM (2003) Interleukin-18 gene-deficient mice show enhanced defense and reduced inflammation during pneumococcal meningitis. J Neuroimmunol 138:31-37

46. Zwijnenburg PJ, van der Poll T, Florguin S, Roord JJ, van Furth AM (2003) Interleukin-10 negatively regulates local cytokine and chemokine production but does not influence antibacterial host defense during murine pneumococcal meningitis. Infect Immun 71:2276-2279

47. Zysk G, Bruck W, Gerber J, Bruck Y, Prange HW, Nau R (1996) Anti-inflammatory treatment influences neuronal apoptotic cell death in the dentate gyrus in experimental pneumococcal meningitis. J Neuropathol Exp Neurol 55:722-728 